experiment by Widdowson and McCance, he emphasized the possible significance of the soup supplied to the children as a source of important nutrients.

Dr. B. S. Platt challenged Dr. Kent-Jones's con. clusion from the Newfoundland experiment that, in view of the health improvement found, highextraction flour could have contributed no more than the enriched white flour actually used. The Wilder report had stated "not all the outward signs of malnutrition had decreased in prevalence. Only those had lessened which could have been affected by addition of vitamin $A$ to margarine and of riboflavin, niacin and thiamine $\left(B_{1}\right)$ to the flour'. In replying, Dr. Kent-Jones interpreted Wilder as attributing the persistent signs to vitamin $\mathrm{C}$ deficiency, not to deficiencies for which the flour could have been held responsible.

Dr. E. Kodicek emphasized that a proportion of nicotinic acid in cereals is in the bound form and unavailable to a number of animals. On the other hand, nicotinic acid added by way of enrichment is wholly available.

Several contributors queried the claim that the public strongly preferred bread made from white flour to that from higher-extraction flour. In this connexion, Dr. J. B. M. Coppock referred to published evidence in support of the claim which had been obtained in a comprehensive survey on consumer preference recently carried out in Glasgow.

The relevance or otherwise of mortality statistics in relation to modern food habits and processing techniques was discussed both by Prof. J. J. Yudkin and Dr. Sinclair. The meeting ended appropriately with a plea by Mr. Bacharach for liberty of choice : members, he said, are free to express views but should not seek to force their adoption.

C. R. JONES

\section{INSTITUTE OF BIOLOGY CONVERSAZIONE}

T

HE annual conversazione of the Institute of Biology, London Branch, was held at the Imperial College of Science and Technology on the evening of June 25. Members and their guests were received in the Students' Union by Prof. P. H. Gregory (head of the Botany Department), F. Howarth (assistant director of the Botanical Laboratories) and Dr. H. O. J. Collier (chairman of the London Branch). A diversity of exhibits was displayed in the Botany Department, by courtesy of Prof. Gregory.

The word 'conversazione' has an Italian derivation and can be defined as a meeting of people for conversation and discussion, particularly on literary, scientific, antiquarian or artistic subjects. The emphasis is, therefore, on the facilities for social intercourse: these were admirably provided in the newly built Students' Union. To say that exhibits take second place to discussion at such a function is not to detract from their importance, for they them. selves are the chief topies of conversation.

The Linnean Society of London, this year's guest society, provided an exhibit illustrating the evolution of the "Species Plantarum" by means of books and manuscripts, as well as items from Linnaeus's natural history collection, including insects, shells and plants. In addition, some of his own annotated works were exhibited and a map of the world showing journeys undertaken by his students to make collections. This was appropriate in the year of the 250th anniversary of the birth of Carl Linné, and provided an interesting comparison with 'Huxleyana', an exhibit showing some of the work of T. H. Huxley and presented by the Zoology Department of the Imperial College.

Each year the London Branch invites one firm of biological suppliers to provide a trade-stand, which, this year, was devoted to stains and reagents for microscopy, modern mounting media, water analysis tablets for field ecology and so on, presented by Edward Gurr, Ltd. Specimen publications were displayed by the Universities Federation for Animal Welfare, the quarterly journal Medical and Biological Illustration and the Institute of Biology. The London Branch's own exhibits included photographs taken during a week-end excursion to the Severn Wildfowl Trust and new trends in biological education.

It is not easy to decide which of the forty or more members' and guests' exhibits most deserve mention. Certainly one of the most original was a 'self-reproducing analogue' (Prof. L. S. Penrose and R. Penrose) recently described in Nature $(179,1183 ; 1957)$. Various suitably shaped wooden or plastic objects, when shaken in a trough, generate precise copies of themselves. The process has been termed pseudobiosynthetics.

Living animals always attract interest and were a feature of several exhibits. In one (P. Hunter-Jones) normal hoppers and adults of the desert locust (Schistocerca gregaria), reared either in crowded conditions or in isolation-phases gregaria or solitariawere compared with albino strains raised under similar conditions. In another (A. T. Thompson) could be seen representatives of some of the exotic grasshoppers kept at the Anti-Locust Research Centre. Cultures were shown of Pharaoh's ant (Monomorium pharaonis) (A. A. Green) and of the American dampwood termite Zootermopsis angusticollis (W. V. Harris and R. M. C. Williams). This insect provides a useful laboratory source of large protozoa, especially species of the genus Trichonympha.

Insects also appeared in exhibits of important species of tsetse fly with distribution maps and colour transparencies of their breeding habitats (Dr. J. R. Busvine), the biology of a British 'ambrosia beetle' (J. M. Baker), the use of 'Terylene' netting for studying the pattern of emergence and decay in a wheat bulb-fly population (J. W. Stephenson and R. W. Dobson) and in preparations of the genitalia of certain beetles (L. P. Lefkovitch). The effect of gamma-rays on ovarian development in the tsetse fly, Glossina morsitans, was illustrated by slides showing the ovaries of a 33-day-old female from an irradiated pupa, which were less developed than those of a 3-day-old female from a normal pupa (W. H. Potts).

In the fields of microbiology were exhibits of membrane filter techniques for concentrating and counting micro-organisms and new selective culture media (W. H. Pierce), some superb photographs of mammalian gametes (Dr. M. W. H. Bishop and Dr. C. R. Austin), preparations showing the cell structure of Cyanophyceae (Dr. J. K. Spearing), an antibody to Trypanosoma vivax present in normal cotton rat serum (Dr. R. J. Terry and Miss V. M. Smith), and tests for the antibiotic sensitivity of bacteria (W. A. Freeman). 
Immunological exhibits also included the effect of insects in causing allergic symptoms in human beings (Dr. A. W. Frankland), a survey of the fungal spore and pollen content of the air (Miss E. D. Hamilton), immunology in agar cells (Dr. J. G. Feinberg, Dr. R. A. Grant and Miss H. Grayson), and gel diffusion methods for immunological assay (Miss B. J. Hayward).

The traditional use of dock leaves to allay the pain of nettle stings has led to the search for an antagonist of 5-hydroxytryptamine in dock-leaf extracts. The presenre of such an antagonist and its action was demonstrated on in vitro preparations of smooth muscle (R. J. Brittain and Dr. H. O. J. Collier). The effect of drugs on the movements of the pig roundworm (Ascaris sp.) was recorded by means of a kymograph technique (Dr. L. G. Goodwin). The apparatus section included a light-scattering photometer (Dr. A. B. Taylor), a device for rapidly collecting samples of insects such as bees (L. Bailey), and apparatus for testing soil and plant tissue for mineral deficiencies (Dr. G. P. L. Miles).

Visitors were able to test their taste-threshold to phenylthiourea, which depends upon a single autcsomal gene (Dr. H. Kalmus). The present writer, like one of his children, was unable to detect any flavour even in the strongest solution provided; his wife could distinguish something, but his other two children responded violently and vulgarly to its bitter taste. In contrast, all members of the family were able to appreciate the delicious home-made wine which formed an exhibit in the hobbies section (H. W. Appleton).

The hobbies of professional biologists are by no means without interest, but have not previously been represented in a London Branch Conversazione. The series of colour photographs of British orchids (J. H. P. Sankey), oil paintings (Dr. J. R. Busvine), drawings of caddis-flies (Dr. N. E. Hicken) and of flowers (Miss D. Potts), in particular, reached a high standard of artistry. Nevertheless, it is by the standard of the biological exhibits that the Conversazione should be judged. Throughout, they showed imagination and skill.

\section{J. L. Cloudsley-Thompson}

\section{WORLD HEALTH ORGANIZATION REPORT FOR 1956}

$\mathrm{N}$ his annual report on the work of the World Health Organization for 1956*, Dr. M. G. Candau, the director-general, reviews the beneficent work of the Organization during the past few years and discusses plans for the future.

Considering malaria first, he recalls the recommendation made by the eighth World Health Assembly, held in Mexico, that eradication of malaria, not its mere control, should be the aim, and that an expert committee, which met after the conference of malariologists held in June 1956, drew up a realistic guide for the planning and carrying out of programmes of eradication of the disease. This policy of eradication was adopted because, in addition to long-range economic considerations, the Anopheles mosquitoes

* Official Records of the World Health Organization No. 75: The Work of WHO 1956-Annual Report of the Director General to the World Mealth Assembly and to the United Nations. Pp. xi $+233+$. 16 pages of photographs. (Geneva: World Health Organization; London: H.M. Stationery Office, 1957.) 6 Swiss francs; 1.0s.; which are the vectors of malaria became resistant to the insecticides used for their control. Research, which must always back up field work, has shown that, in some instances, mosquitoes resistant to DDT can be controlled by insecticides of the benzene hexachloride type, but that, in some parts of Greece, the mosquitoes are resistant to both these groups of insecticides and, wherever this occurs, other methods of control have to be devised. Preliminary studies promoted by the World Health Organization have shown that the distribution to peoples of salt. containing antimalarial drugs has given encouraging results. Two other antimalarial problems under investigation, both of them important in Africa, are the sorption of insecticides by the mud walls of houses, and the behaviour of the chief vector of malaria in Africa, Anopheles gambiae.

The section of the report devoted to malaria is especially interesting because it is illustrated not only by photographs of antimalarial work in Iraq and Mexico, but also by four valuable maps, which show at a glance the distribution of antimalarial activities in Europe, Africa, Asia and North and South America and the progress to date, so far as the latest information permits, of control and eradication programmes. These maps show, for example, that eradication is practically or fully achieved in the western United States and the Californian region, in Puerto Rico, Northern Chile, French Guiana, parts of Venezuela and British Guiana, in the greater part of Ceylon and, in Europe, in Italy, Corsica, Sardinia, Cyprus and Crete. Elsewhere the vigorous campaigns assisted by the World Health Organization are likely, in due course, to rid the world of a disease which is still one of the major menaces to mankind.

This cannot be done, however, without the research work which is, the director-general rightly insists, "the real backbone through which the Organization is striving to promote World Health". It is also a basic function of the World Health Organization to pool all available scientific and technical knowledge, to appraise this knowledge constantly and to study how best it can be applied to problems of public health wherever they occur. Malaria is not by any means the only disease transmitted by insect vectors, and the general problem of the resistance of vectors of disease to insecticides has been tackled by a survey of research. Experts appointed by the World Health Organization have visited more than one hundred laboratories concerned with this problem and the gaps in our knowledge have been defined. Coordination of the work of several scientific institutes has developed basic methods of measuring the susceptibility or resistance of vector populationsfor example, the lice of man - with the result that the World Health Organization is now able to advise the best method of control, and there has in consequence been a betterment of the control of typhus fever, which is transmitted by lice.

In a different field of work a series of projects initiated by the World Health Organization and its experts has greatly advanced the control of rabies. The efficacy of hyperimmune serum has been demonstrated, and field trials in Iraq on the use of serum in persons exposed to rabies, in Spain on the local treatment of wounds inflicted by animals suffering from rabies, in Malaya and Israel on new vaccines for the control of rabies in animals, and in France and the United States on the standardization of the potency of vaccines and sera, have all contributed 